\title{
Effect of Transformer Parameters and Line Reactor on Power Flows in High-Voltage Systems
}

\author{
Ngo Duc Minh*, Le Tien Phong \\ Email address: \\ ngoducminh@tnut.edu.vn (N. D. Minh) \\ ${ }^{*}$ Corresponding author
}

Electrical Faculty, Thai Nguyen University of Technology, Thai Nguyen, Viet Nam

To cite this article:

Ngo Duc Minh, Le Tien Phong. Effect of Transformer Parameters and Line Reactor on Power Flows in High-Voltage Systems. American Journal of Electrical Power and Energy Systems. Vol. 8, No. 3, 2019, pp. 77-85. doi: 10.11648/j.epes.20190803.12

Received: June 14, 2019; Accepted: July 11, 2019; Published: July 24, 2019

\begin{abstract}
This paper focuses on the effect of transformer parameters and a line reactor on distribution of power flows in a high-voltage substation and transmission lines. Four case studies that have different values of transformer parameters including rated power, short-circuit impedance and reactance/resistance ratio are supposed in this research. Basing on power flows on transformers in case of the parallel operation, load factor of each transformer and operating parameters are considered in above case studies. Moreover, a line reactor is proposed in this paper to regulate power flows in a system having two power sources. Four operating modes of the proposed line reactor are defined by changing on/off states of switches in this device to modify the value of impedance. The effect of the line reactor on power received from sources and power flows on transmission lines is evaluated in its all modes. Research results are carried out by the ETAP 16.0 software and present high accuracy and reliability for the proposed problems. Research contributions help dispatchers understand the essence of power transmission process, solve real problems and give out effective solutions to operate high-voltage systems.
\end{abstract}

Keywords: Line Reactor, Parallel Operation, Transformer Parameter, ETAP Software, Power Flow, Voltage Angle, Voltage Module

\section{Introduction}

Transmission systems are composed by power lines and substations, where power substations have some transformers. The dispatch center in each power system regulates power flows in whole system under the support of the supervisory control and data acquisition and expert system to analyze all system parameters fast [1]. This center intervenes voltage module and angle and some controllable devices to regulate power flows in whole system, including both in power substations and on power lines.

In power substations, the best method to operate transformers is parallel because it can help toequilibrium power load and prolong life time for all devices. All transformers in the substation must be completely met the similar in rated voltage at primary and secondary sides, group of winding, short-circuit impedance (Z\%), reactance/resistance $(\mathrm{X} / \mathrm{R})$ ratio $[2,3]$. In real operating process, there are some differences of transformer parameters because of activating on-load tap changer or replacing one of transformers when having any faults related to transformers $[4,5]$. They lead to the difference of power flows on transformers and affect to the reliability of relaying protection.

In transmission system, both voltage angle and module can be controlled to regulate power flows on transmission lines but only voltage angle is the best choice due to the limitation of rated voltage. In real operating process, the difference of voltage angle between sources is able to reach to a large value while switching circuit breakers that affects badly to device insulator and electric quality. Some flexible alternating current transmission system (FACTS) devices such as static var compensator, static synchronous compensator, unified power flow controller,... were proposed to solve this problem [6-9]. They can help to meet the requirement of compensative power or regulate voltage angle. This solution has also had some disadvantages because sources are governed by generators, line and types of electric load. Moreover, it makes high cost to place these devices in whole system and does not bring economic benefit because 
the number of switching sources in high-voltage grids is very small. Line reactors that have low cost and can help to limit switched current were proposed to in medium voltage grids [10-14]. They can be applied to insert a reactance to a line that can change voltage angle. Due to this principle, line reactors are able to apply in high-voltage grids when combined switching devices. Up to now, there has not had any research about these devices in high-voltage grids so it needs to evaluate the their effect on the distribution of power flows in whole system.

A simulation tool that has been often used to analyze power system in steady state recently is ETAP software, a production of Operation Technology Inc. It has many blocks to simulate generators, transformers, power lines, electric load, renewable sources, swing source,... It is a strong and reliable tool using the adaptive Newton-Raphson method to completely and accurately determine all operating parameters such as bus voltage (module and angle), active and reactive power flows on lines,... $[15,16]$. Due to this reason, ETAP software will be used as a reliable solution to evaluate proposed research problems.

Because of above analysis, it needs to have more detail evaluations about the effect of transformer parameters and line reactors on the distribution of power flows. All problems will be make more clear in this paper by simulating a system on ETAP software corresponding to different case studies and operating states. In the next section, a power system with the presence of lines and a power substation having double two-winding transformers is constructed a research object in this paper. Section III will give out some simulation results to evaluate the effect of transformer parameters on power flows in the substation. Case studies in this section will consider the difference of transformer parameters. The effect of a line reactor with different impedance values on power flows going on lines will be simulated and evaluated in section IV. The last section will present some conclusions and contributions.

\section{Distribution of Power Flows in a System with the Presence of a High-Voltage Substation}

A high-voltage system with double two-winding transformers, sources, power lines and a line reactor is proposed in Figure 1. All sources in Figure 1 are swing generations that can meet power as requirement of load and maintain stably for whole system. All lines in Figure 1 characterize distances between grids and loads. They also link sources (Grid 1 and Grid 2), transformers (T1 and T2) and loads.

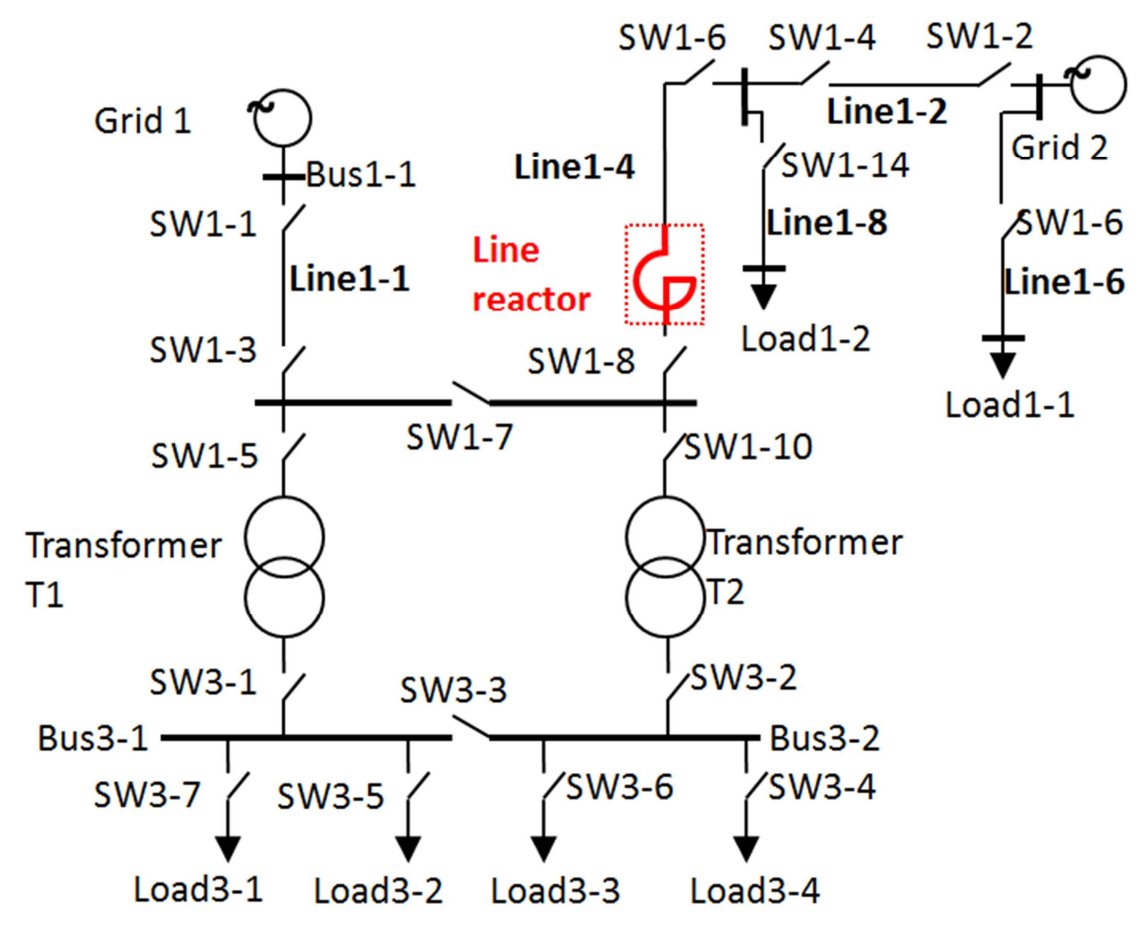

Figure 1. Single-line diagram of the system.

In almost power substations, transformer parameters are often designed the same and transformers are often worked in parallel to ensure the reliability and the same working life for all devices. Circuit breakers (SW) play an important role to switch sources providing electric to loads. In opened lines such as line 1-8 or line 1-6, active and reactive power is only transferred in one direction from a source to load. In lines connecting two sources, active and reactive power flows can be bidirectional depending on source parameters and the presence of the line reactor as depicted in Figure 2, where blue arrows present active power flows, brown arrows present reactive power flows and direction of narrow presents positive value. 


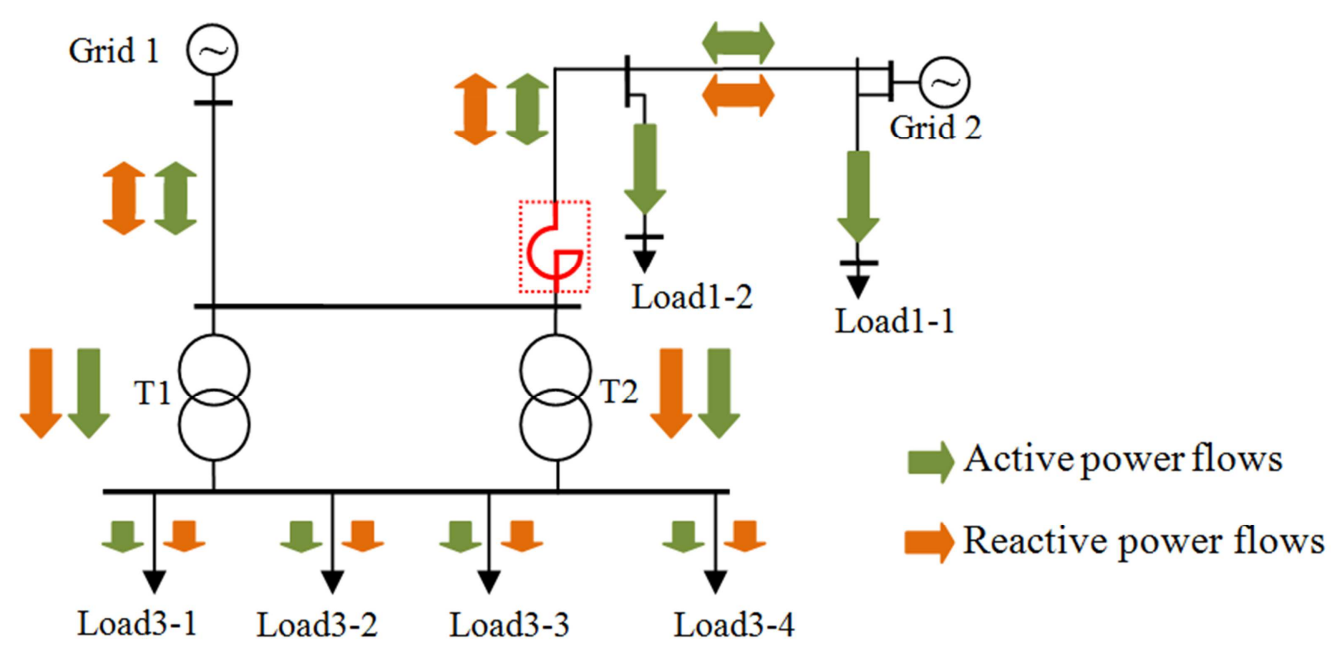

Figure 2. Distribution of power flows in the system.

To evaluate the difference of power flowsin the substation, some case studies related to transformer parameters are considered and presented in Table 1.

Table 1. Case studies related to transformer parameters.

\begin{tabular}{lll}
\hline Case studies & & \\
\hline Rated power is & 1 & $\mathrm{Z} \%$ and $\mathrm{X} / \mathrm{R}$ ratio are the same \\
the same & 2 & $\mathrm{Z} \%$ is the same and $\mathrm{X} / \mathrm{R}$ ratio is different \\
Rated power is & 3 & $\mathrm{Z} \%$ is the same \\
different & 4 & $\mathrm{Z} \%$ is different \\
\hline
\end{tabular}

To regulate power flows in lines, the line reactor is designed to limit switching current when synchronizing two sources. The power circuit of the proposed line reactor is described in Figure 3.

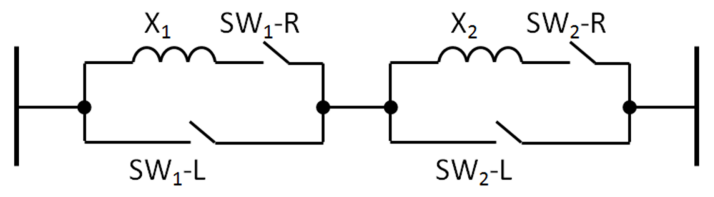

Figure 3. Power circuit of line reactor.

Due to having multi-level structure with SWs and reactor blocks (presented by $\mathrm{X}_{1}$ and $\mathrm{X}_{2}$ reactance), its reactance can be regulated by changing on/off states of SWs. Moreover, SWs can be operated in a logic method to create the largest number of operating modes corresponding to different operating requirements.

\section{Evaluate the Effect of Transformer Parameters on Power Flows in the Substation}

To evaluate the effect of transformer parameters, transformers work in parallel and the state of SW1-8 is off. It means that the substation is only supplied power from Grid 1. Parameters of sources, lines and loads are represented in Table 2, Table 3and Table 4.
Table 2. Source parameters.

\begin{tabular}{|c|c|c|c|c|}
\hline Source name & Type & \multicolumn{2}{|c|}{ Voltage magnitude } & Voltage angle \\
\hline Grid 1 & swing & $115.5 \mathrm{kV}$ & \multicolumn{2}{|c|}{10 degree } \\
\hline Grid 2 & swing & $115.5 \mathrm{kV}$ & \multicolumn{2}{|c|}{2 degree } \\
\hline \multicolumn{5}{|c|}{ Table 3. Line parameters. } \\
\hline Line name & $\begin{array}{l}\text { Length } \\
(\mathrm{km})\end{array}$ & $\begin{array}{l}\text { Resistance } \\
(\Omega / \mathbf{k m})\end{array}$ & $\begin{array}{l}\text { Reactance } \\
(\Omega / \mathbf{k m})\end{array}$ & $\begin{array}{l}\text { Admittance } \\
(\mathrm{S} / \mathrm{km})\end{array}$ \\
\hline Line 1-1 & 30 & 0.087 & 0.185826 & 0.0000063 \\
\hline Line 1-2 & 30 & 0.174002 & 0.398161 & 0.0000029 \\
\hline Line 1-4 & 20 & 0.174002 & 0.398161 & 0.0000029 \\
\hline Line 1-6 & 20 & 0.174002 & 0.398161 & 0.0000029 \\
\hline Line $1-8$ & 20 & 0.087 & 0.185826 & 0.0000063 \\
\hline
\end{tabular}

Table 4. Load parameters.

\begin{tabular}{lll}
\hline Line name & Active power & Reactive power \\
\hline Load 3-1 & 19.3 & 5.43 \\
Load 3-2 & 14.5 & 4.07 \\
Load 3-3 & 21.3 & 5.97 \\
Load 3-4 & 8.53 & 5.29 \\
Load 1-1 & 51.3 & 31.8 \\
Load 1-2 & 25.7 & 15.9 \\
\hline
\end{tabular}

Power flow on each transformer is determined by using ETAP software in case studies as shown in Table 1. They have some difference between rated power, $\mathrm{Z} \%$ and $\mathrm{X} / \mathrm{R}$ ratio.

\subsection{Transformers Having the Same Value of Rated Power}

Detail parameters for transformers to simulate on ETAP software are represented in Table 5.

Table 5. Transformer parameters in case studies having the same value of rated power.

\begin{tabular}{lllllll}
\hline $\begin{array}{l}\text { Case } \\
\text { study }\end{array}$ & $\begin{array}{l}\text { Transformer } \\
\text { name }\end{array}$ & $\begin{array}{l}\text { Voltage } \\
\text { ratio }\end{array}$ & $\begin{array}{l}\text { Rated } \\
\text { power }\end{array}$ & Z\% & $\begin{array}{l}\text { X/R } \\
\text { ratio }\end{array}$ & $\begin{array}{l}\text { Tap } \\
\text { setting }\end{array}$ \\
\hline 1 & T1 and T2 & & 40 & & 45 & $2.5 \%$ \\
2 & T1 & $110 / 35$ & MVA & 12.5 & 45 & $2.5 \%$ \\
& T2 & & & 20 & \\
\hline
\end{tabular}


Values of active, reactive and apparent power flow on each transformer are shown in Table 6.

Table 6. Power flows on transformers in case studies having the samevalue of rated power.

\begin{tabular}{lllll}
\hline $\begin{array}{l}\text { Case } \\
\text { study }\end{array}$ & $\begin{array}{l}\text { Transformer } \\
\text { name }\end{array}$ & $\begin{array}{l}\text { Active power } \\
\text { (MW) }\end{array}$ & $\begin{array}{l}\text { Reactive } \\
\text { power (MVAr) }\end{array}$ & $\begin{array}{l}\text { Apparent } \\
\text { power (MVA) }\end{array}$ \\
\hline 1 & T1 and T2 & 31.9 & 14 & 34.83 \\
2 & T1 & 31.7 & 14.4 & 34.8 \\
& T2 & 32.1 & 13.5 & 34.8 \\
\hline
\end{tabular}

In case study 1 , values of active, reactive and apparent power are completely similar because of completely similar transformer parameters. In case study 2, values of active and reactive power on the transformer having smaller value of
$\mathrm{X} / \mathrm{R}$ ratio are larger than values on the other transformer. It means that the smaller value of $\mathrm{X} / \mathrm{R}$ ratio is, the larger values of power flow on transformers is. Simulation results for whole system in case study 1 and 2 are shown in Figure 4 and Figure 5. In both these case studies, value of power supplied from grid 1 is $64.7+\mathrm{j} 27.6 \mathrm{MVA}$ and from grid 2 is $78.8+\mathrm{j} 46.9 \mathrm{MVA}$. It is easy to see that supplied power from grid 1 is completely equal to total power on transformers and supplied power from grid 2 is equal to total power of load1-1, load1-2 and power loss in lines. Power from source 2 could not be transferred to the substation due to the off state of SW1-8. Furthermore, the balance of load requirement and power on transformer is always ensured.

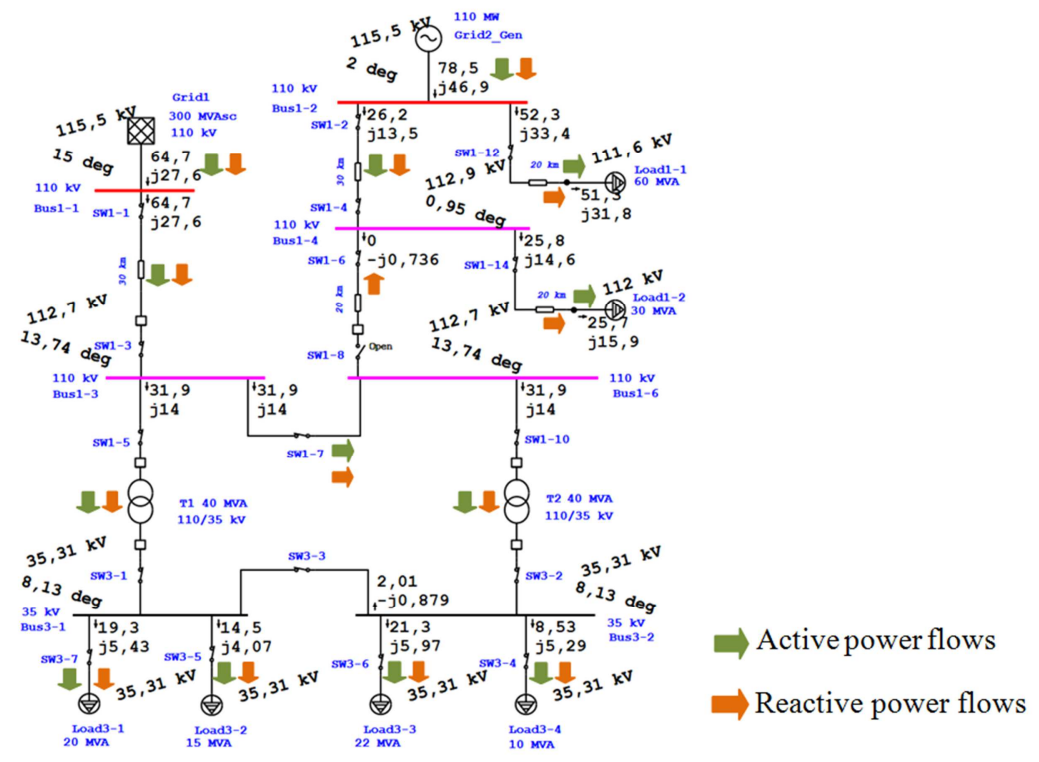

Figure 4. Simulation results for whole system in case study 3.

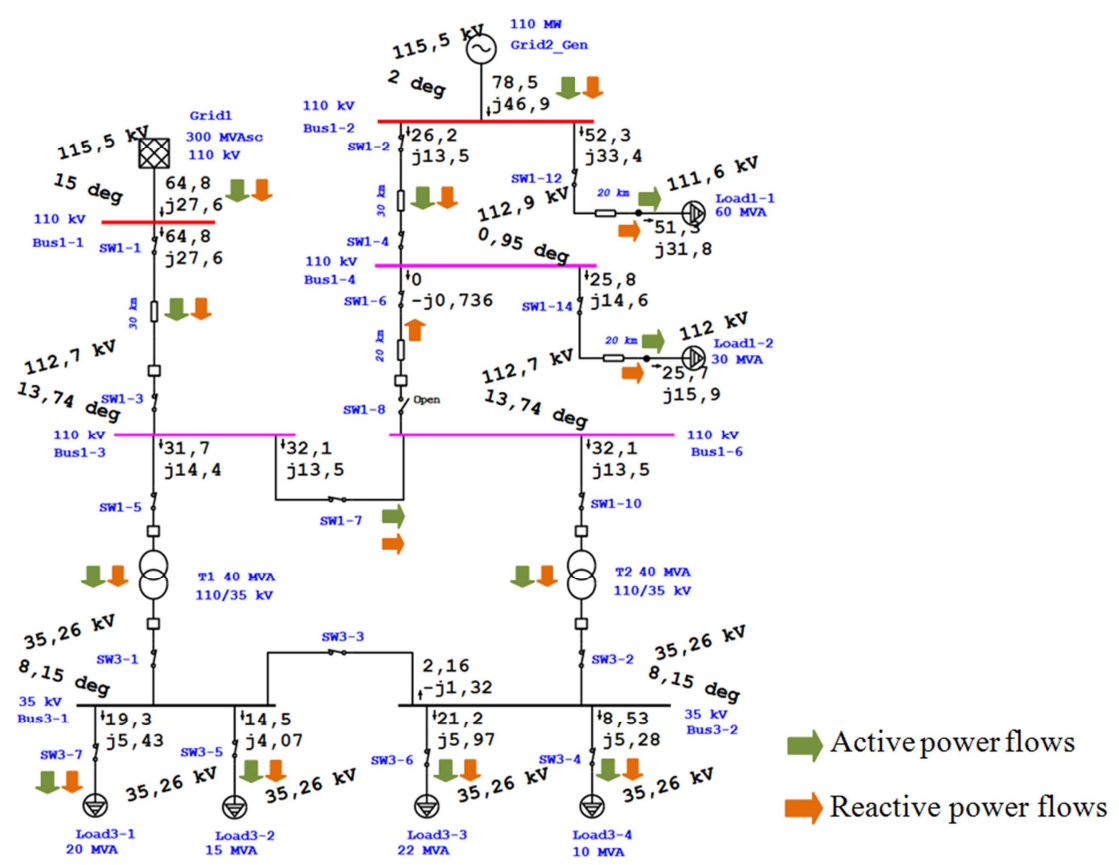

Figure 5. Simulation results for whole system in case study 4. 


\subsection{Transformers Having Different Value of Rated Power}

Detail parameters for transformers to simulate on ETAP software are represented in Table 7 . Values of active, reactive and apparent power flow on each transformer are shown in Table 8.

Table 7. Transformer parameters in case studies having different values of rated power.

\begin{tabular}{|c|c|c|c|c|c|c|}
\hline $\begin{array}{l}\text { Case } \\
\text { study }\end{array}$ & $\begin{array}{l}\text { Transformer } \\
\text { name }\end{array}$ & $\begin{array}{l}\text { Voltage } \\
\text { ratio }\end{array}$ & $\begin{array}{l}\text { Rated power } \\
\text { (MVA) }\end{array}$ & Z\% & $\begin{array}{l}\mathrm{X} / \mathrm{R} \\
\text { ratio }\end{array}$ & $\begin{array}{l}\text { Tap } \\
\text { setting }\end{array}$ \\
\hline \multirow{2}{*}{3} & $\mathrm{~T} 1$ & \multirow{3}{*}{$110 / 35$} & 40 & & & \\
\hline & $\mathrm{T} 2$ & & 25 & 12.5 & 45 & \multirow{2}{*}{$\begin{array}{l}2.5 \% \\
2.5 \%\end{array}$} \\
\hline 4 & $\begin{array}{l}\mathrm{T} 1 \\
\mathrm{~T} 2\end{array}$ & & $\begin{array}{l}40 \\
25\end{array}$ & $\begin{array}{l}12.5 \\
10\end{array}$ & $\begin{array}{l}45 \\
20\end{array}$ & \\
\hline
\end{tabular}

Table 8. Power flows on transformers in case studies having different values of rated power.

\begin{tabular}{llllll}
\hline $\begin{array}{l}\text { Case } \\
\text { study }\end{array}$ & $\begin{array}{l}\text { Transformer } \\
\text { name }\end{array}$ & $\begin{array}{l}\text { Active } \\
\text { power } \\
\text { (MW) }\end{array}$ & $\begin{array}{l}\text { Reactive } \\
\text { power } \\
\text { (MVAr) }\end{array}$ & $\begin{array}{l}\text { Apparent } \\
\text { power } \\
\text { (MVA) }\end{array}$ & $\begin{array}{l}\text { Load } \\
\text { factor }\end{array}$ \\
\hline \multirow{2}{*}{3} & T1 & 39.1 & 18.3 & 43.1 & 1.08 \\
& T2 & 24.4 & 11.4 & 27 & 1.08 \\
4 & T1 & 35.6 & 16.6 & 39.3 & 0.98 \\
& T2 & 28.1 & 12.2 & 30.7 & 1.23 \\
\hline
\end{tabular}

Simulation results for whole system in case study 3 and 4 are shown in Figure 6 and Figure 7.

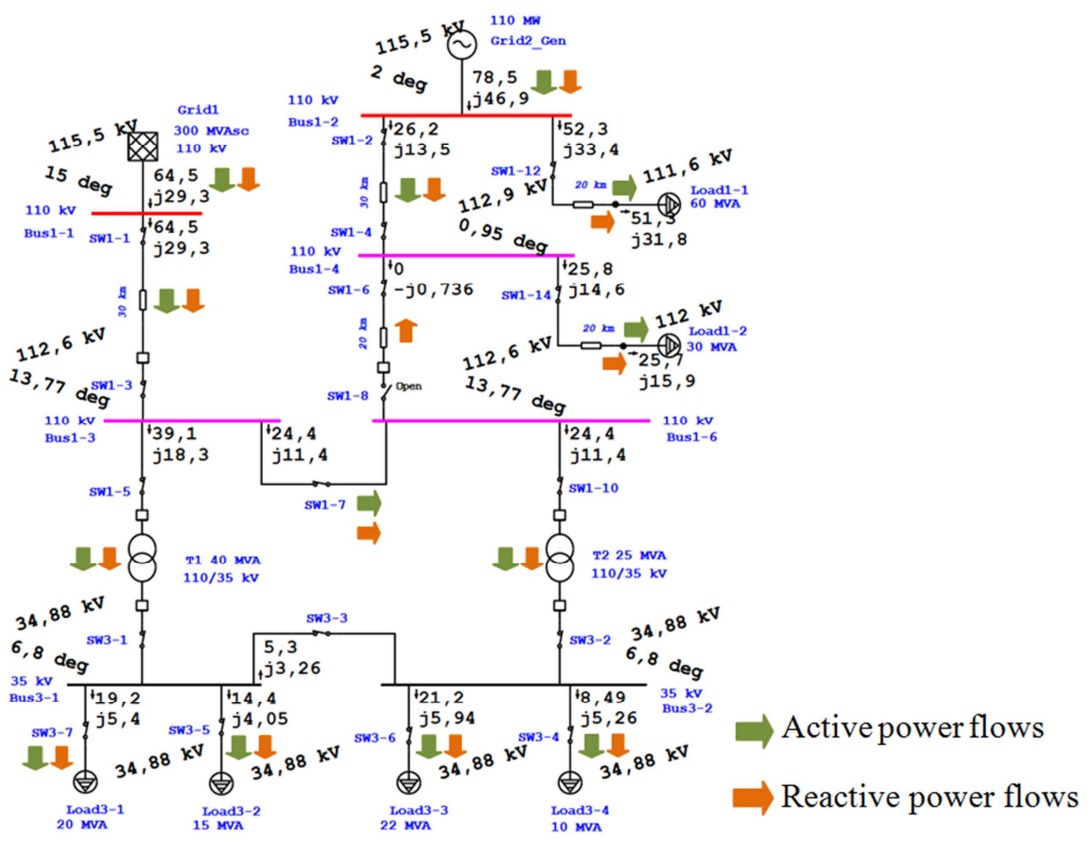

Figure 6. Simulation results for whole system in case study 3.

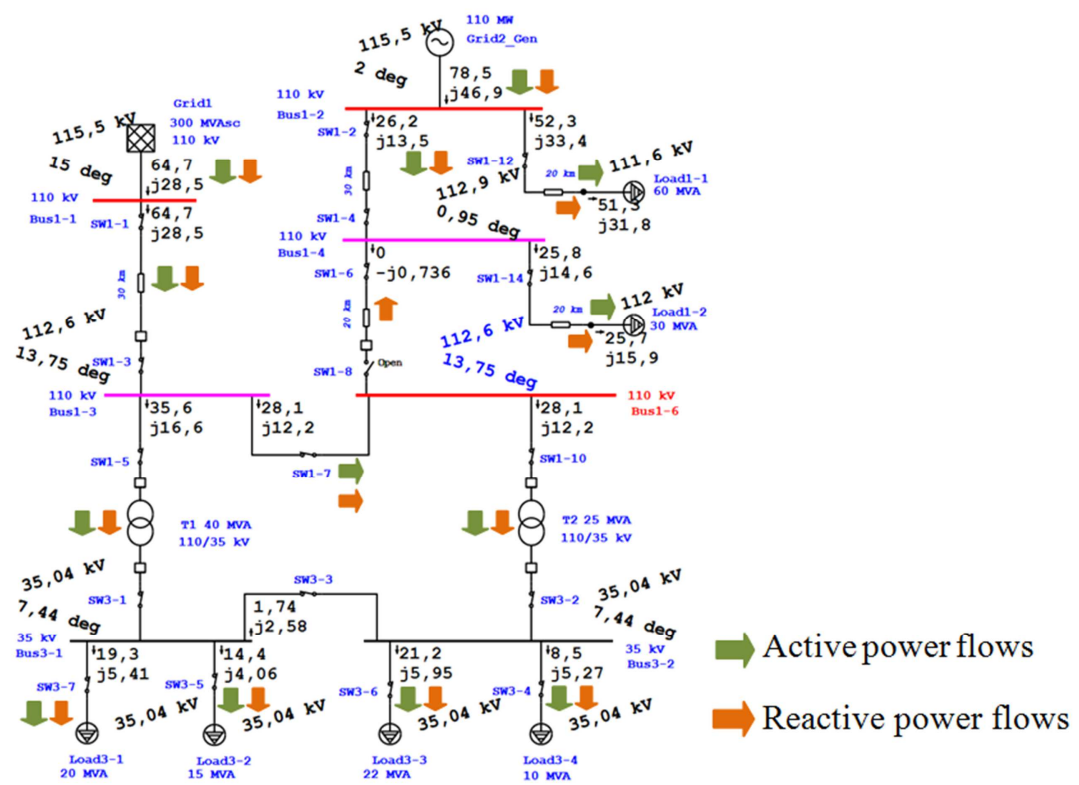

Figure 7. Simulation results for whole system in case study 4. 
In both these case studies, values of power flows on transformers are large different corresponding to the value of rated power. In case study 3 , load factors of power flows on transformers are completely similar due to the similar value of $\mathrm{X} / \mathrm{R}$ ratio although the values of rated power are the same. In case study 4 , load factors of power flows on transformers are completely different, where the larger value of rated power is, the smaller value of load factor is. It means that $Z$ and $\mathrm{X} / \mathrm{R}$ ratio play an important role to restrict power flows on transformers. In both these case studies, value of power supplied from grid 1 is $64.5+\mathrm{j} 29.3 \mathrm{MVA}$ and from grid 2 is $78.5+\mathrm{j} 46.9 \mathrm{MVA}$. It is easy to see that supplied power from grid 1 is also completely equal to total power on transformers and supplied power from grid 2 is also equal to total power of load1-1, load1-2 and power loss in lines. Power from source 2 could not be transferred to the substation due to the on state of SW1-8. Furthermore, the balance of load requirement and power on transformer is always ensured.

Through simulation process, we also recognize the difference of voltage angle at primary and secondary sides in these case studies although parameters of source 1 is fixed. Voltage angle at the primary side in case study 1 is 8.74 degree and in case study 2 is 13.74 degree. Voltage angle at the secondary side in case study 1 is 3.13 degree and in case study 2 is 8.15 degree. Voltage angle at the primary side in case study 3 is 8.77 degree and in case study 4 is 13.75 degree. Voltage angle at the secondary side in case study 3 is 1.8 degree and in case study 4 is 7.44 degree. Compared case study 1 and 3, values of rated power affects much to voltage angle at the secondary side of transformers. Compared case study 2 and 4, values of rated power do not affect much to voltage angle at the secondary side of transformers. Generally, values of rated power, $\mathrm{Z}$ and $\mathrm{X} / \mathrm{R}$ ratio cause to reduce the value of voltage angle at primary and secondary sides of transformers and affect much to power flows on transformers. These simulation results in case studies from 1 to 4 presented the reliability of ETAP software to analyze power systems.

\section{Evaluate the Effect of the Line Reactor on Power Flows in the System}

To evaluate the effect of a line reactor on power flows in whole system, the state of SW1-8 is converted from off state to on state and a line reactor is placed in series on line 1-4. It means that load requirement can be met by both sources. Parameters of sources, loads and lines were shown in Table 2, Table 3 and Table 4. Parameters of the line reactor are represented in Table 9.

Table 9. Parameters of line reactor.

\begin{tabular}{llll}
\hline Block name & Rated current & Impedance $(\boldsymbol{\Omega})$ & X/R ratio \\
\hline X1 & 500 & 50 & $100 / 0.5$ \\
X2 & 500 & 30 & $100 / 0.5$ \\
\hline
\end{tabular}

To operate the line reactor, its operating modes can be created by combining on/off states of SW1-R, SW1-L, SW2$\mathrm{R}$ andSW2-L. These modes will contribute different values of reactance to the system as depicted in Table 10.

Table 10. Operating modes of line reactor.

\begin{tabular}{llllll}
\hline Mode & SW1-R & SW2-R & SW1-L & SW2-L & Impedance \\
\hline 1 & Close & Close & Open & Open & 0 \\
2 & Open & Close & Open & Close & $80 \Omega$ \\
3 & Open & Close & Close & Open & $50 \Omega$ \\
4 & Close & Open & Open & Close & $30 \Omega$ \\
\hline
\end{tabular}

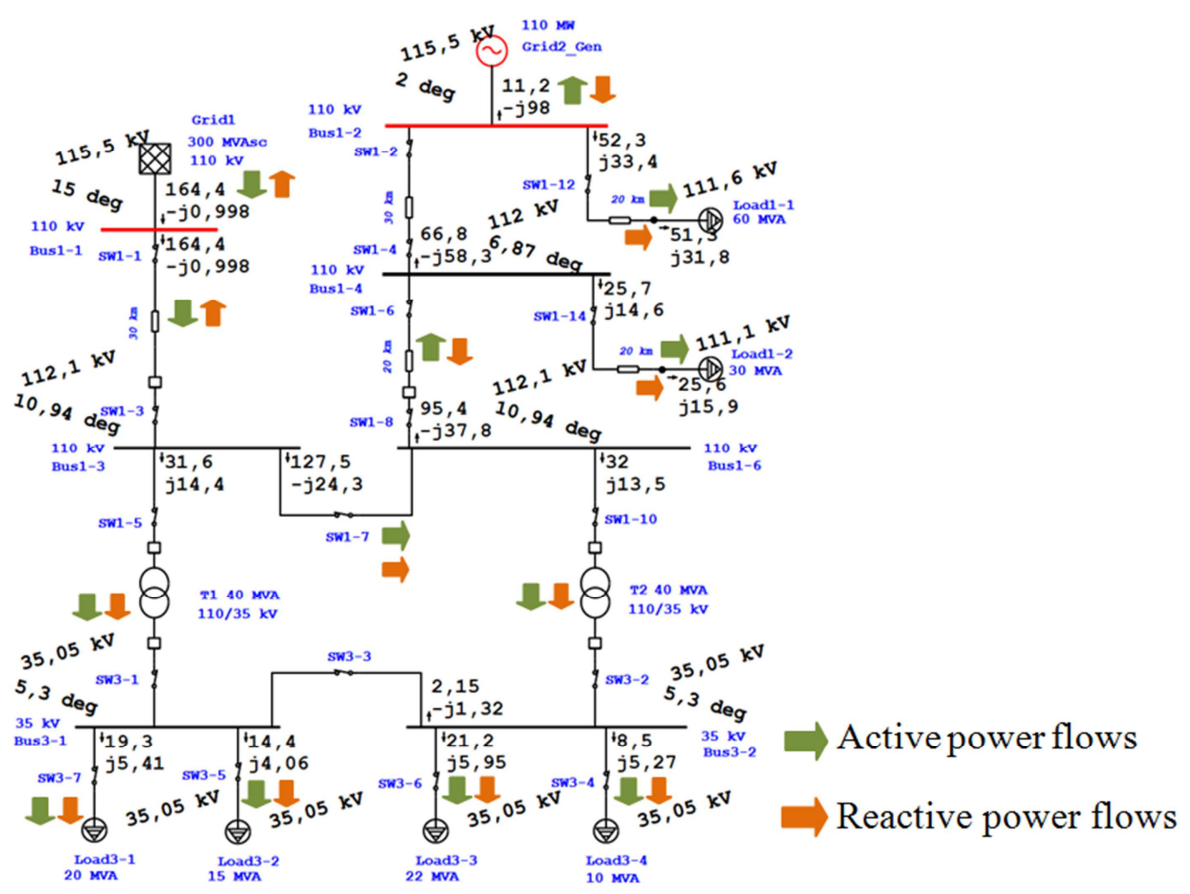

Figure 8. Simulation results in mode 1 ofthe line reactor. 
In mode 1 , value of reactance contributing to the system is 0 (the same as not using the line reactor). Simulation results to analyze the system in this mode are shown in Figure 8. In this mode, source 1 generated 164.4 MW active power and received $0.998 \mathrm{MVAr}$ reactive power while source 2 received 11.2 MW active power and generated 98MVArreactive power. After switching state of SW1-8, grid 1 and grid 2 changes operating states: grid 1 received reactive power and grid 2 received active power. It means that in system without contributing reactance of the line reactor, voltage angle of sources can affect much to power flows, change operation state from generating power to consuming power. Power flow on line1-1 also increased over the thermal limitation of this line.

The line reactor contributed $80 \Omega$ in mode 2, $50 \Omega$ in mode 3, $30 \Omega$ in mode 4 to the system. Simulation results in these modes are represented in Figure 9, Figure 10 and Figure 11.

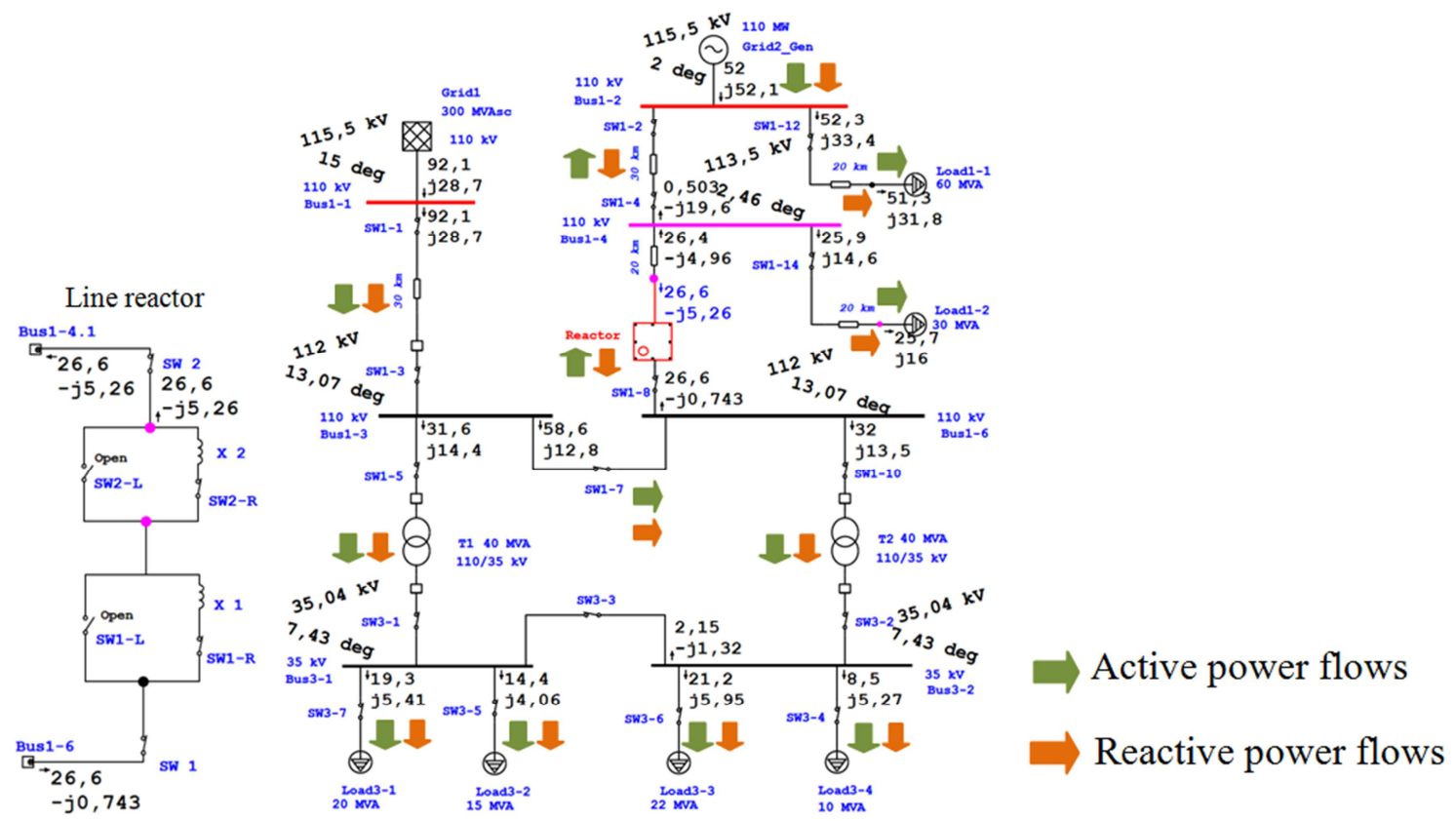

Figure 9. Simulation results in mode 2 of the line reactor.

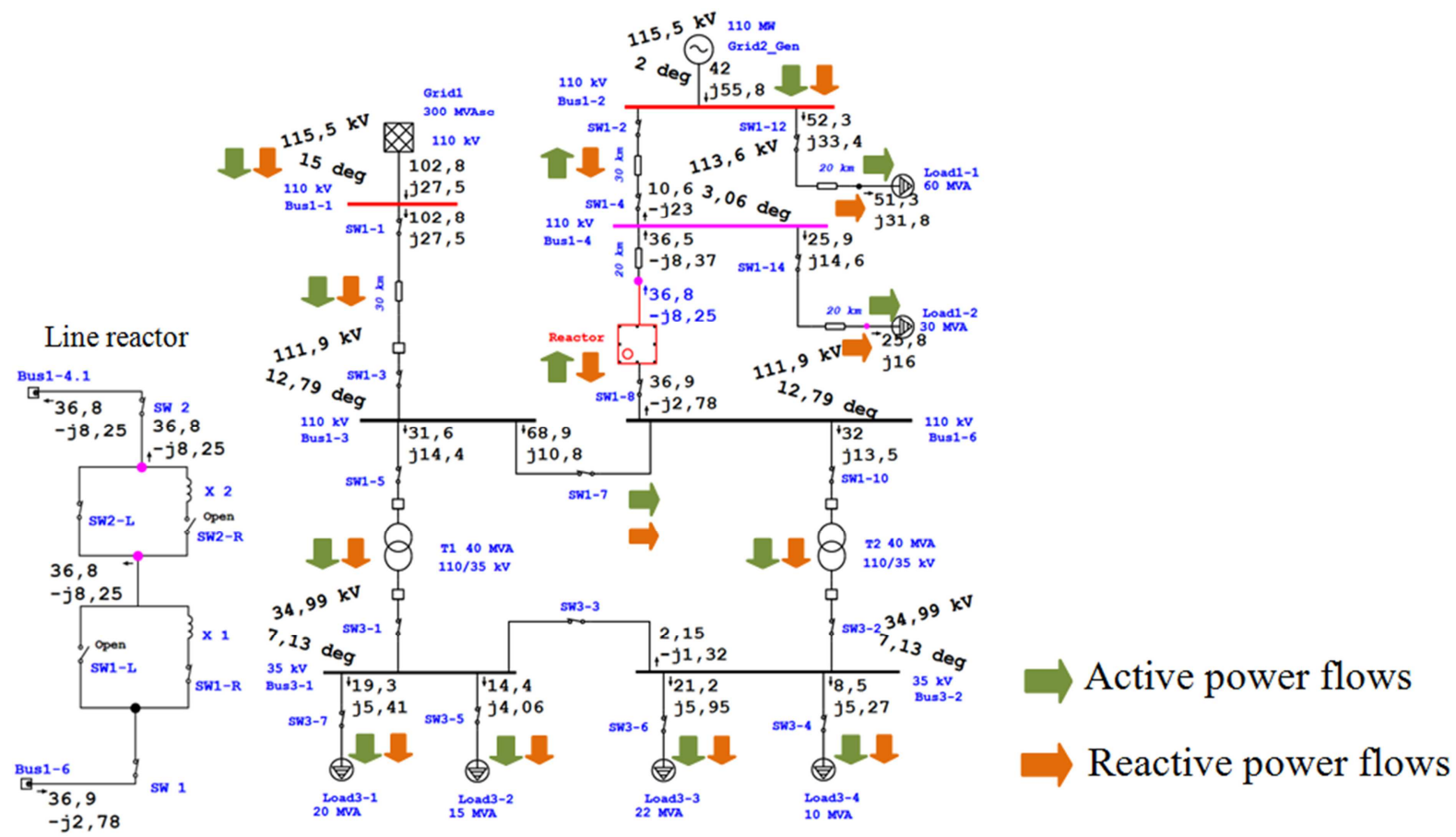

Figure 10. Simulation results in mode 3 of the line reactor. 


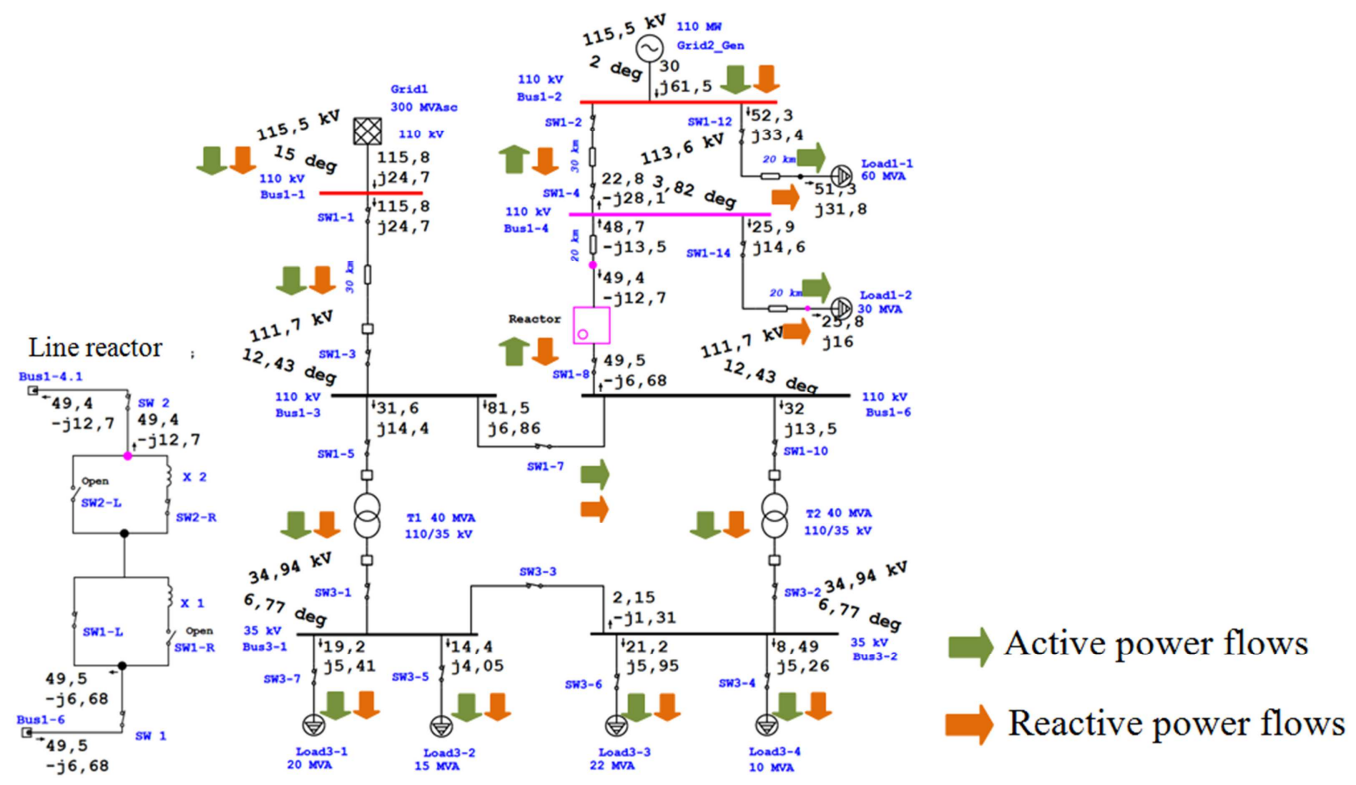

Figure 11. Simulation results in mode 4 of the line reactor.

Values of power flows generating from sources and on the line reactor are represented in Table 11.

Table 11. Power flows from sources and on line reactor.

\begin{tabular}{llll}
\hline Mode & Source 1 & Source 2 & Line reactor \\
\hline 1 & $164.4-\mathrm{j} 0.998$ & $-11.2+\mathrm{j} 98$ & $95.4-\mathrm{j} 37.8$ \\
2 & $92.1+\mathrm{j} 28.7$ & $52+\mathrm{j} 52.1$ & $26.6-\mathrm{j} 0.743$ \\
3 & $102.8+\mathrm{j} 27.5$ & $42+\mathrm{j} 55.8$ & $36.9-\mathrm{j} 2.78$ \\
4 & $115.8+\mathrm{j} 24.7$ & $30+\mathrm{j} 61.5$ & $49.5-\mathrm{j} 6.68$ \\
\hline
\end{tabular}

In both case studies 2, 3 and 4, both sources generated active and reactive power because of the effect of the line reactor. Voltage angle also changed corresponding to the variation of reactance of the line reactor. Moreover, power flows on the line 1-1 and line 1-4 reduced to the smallest value in mode 2 . Due to this benefit, the line reactor can help to reduce the switching current and limit the over thermal phenomenon in operating process.

\section{Conclusion}

Different transformer parameters, including rated power, impedance and $\mathrm{X} / \mathrm{R}$ ratio, are considered in this paper to evaluate the their effect on power flows in substations. This paper also proposed to implement a line reactor on a highvoltage transmission line to limit the current when switching source process. The new contribution is the evaluation of reactance of the line reactor on power flows mobilizing from source in real operating process.

ETAP software was used to determine all information about power flows in whole system in steady state. Simulation results showed that any difference of transformer parameters caused differences of active and reactive power on each transformer. Moreover, load factors were also different and caused overload on one transformer and underload on another transformer. For the line reactor, operating modes created by on/off states of SW help to contribute different values of reactance. Simulation results about modes of the line reactor showed that it can help to regulate power flows on lines, reduce them under thermal limitation and change voltage angle at buses in whole system.

Research contributions of this paper help operators have information about operating states that can happen in the substation whenever having any different transformer parameters. They also help to reduce wrong response of relaying protection, power loss in substations and avoid the difference of both voltage module and angle at the secondary side. Basing on simulation, dispatchers can suppose some scenarios to completely evaluate and give out suitable solutions to simulate response of all units in whole system before executing devices in real operation process. This paper is an important document to teach theory and practical for students in power system field and train operators in real substations.

\section{Acknowledgements}

This study is partly supported by Science research project (ID: T2017 B 10), Thai Nguyen University, Viet Nam.

\section{Declaration}

All authors have disclosed no conflicts of interest.

\section{References}

[1] YooJin Kwon, SangYoum Lee, Ralph King, Jong In Lim and Huy Kang Kim (2019), "Behavior Analysis and Anomaly Detection for a Digital Substation on Cyber-Physical System", Electronics, Vol 8, Issue 3, ISSN 2079-9292.

[2] Mohammad A. Lakdawala, Vaibhav Patel, Bhavik Patel, Pushprajsinh Jadeja (2017), “A Review on Load Sharing of Transformer", International Journal of Science Technology \& Engineering, Volume 3, Issue 7, ISSN (online): 2349-784X. 
[3] Álvaro Jaramillo-Duque, Nicolás Muñoz-Galeano, José R. Ortiz-Castrillón, Jesús M. López-Lezama (2018), "Power Loss Minimization for Transformers Connected in Parallel with Taps Based on Power Charge ability Balance", Energies, Vol. 11, ISSN 1996-1073.

[4] Adebayo I. G., Adejumobi, I. A., Adepoju, G. A (2013), "Power Flow Analysis Using Load Tap - Changing Transformer (LTCT): A Case Study of Nigerian 330kV Transmission Grid System", International Journal of Engineering and Advanced Technology (IJEAT), Volume-2, Issue-3, ISSN: $2249-8958$

[5] Dr. V. S. Vakula, Mr. chetlapalli Sai Praveen, Mr. Niddan Rames (2017), "Automatic control of On Load Tap Changing of Transformers for Enhancement of Voltage Stability", International Journal of Engineering Development and Research, Volume 5, Issue 3, ISSN: 2321-9939.

[6] Sidnei do Nascimento and Maury M. Gouvêa Jr (2017), "Voltage stability enhancement in power systems with automatic facts device allocation", Proceeding of International Conference on Energy and Environment Research, ICEER 2016, Barcelona, Spain, ISSN: 2278 - 1323.

[7] Mallesh Gadeppanavar, Vinay Pattanashetti (2013), "Improving Efficiency in Transmission and Distribution System", International Journal of Emerging Technology and Advanced Engineering, Vol 3, Issue 3, ISSN 2250-2459.

[8] Vireshkumar G. Mathad, Basangouda F. Ronad (2013), "Review on Comparison of FACTS Controllers for Power System Stability Enhancement", International Journal of Scientific and Research Publications, Volume 3, Issue 3, ISSN: 2250-3153.

[9] Raju Pandey, A. K. Kori (2012), "Real and Reactive Power flow Control Using Flexible AC Transmission System connected to a Transmission line: a Power Injection Concept", International Journal of Advanced Research in Computer
Engineering \& Technology (IJARCET), Volume 1, Issue 6, ISSN: $2278-1323$.

[10] Y. V. Sridhar, Haitham Safar, Nilesh Modi, Yousuf Ali, Yacoub Al-Dashti (2013), "Techno-Economic Study of Series Current Limiting Reactor and Its Impact in the $11 \mathrm{KV}$ Network with Harmonic Pollution", Journal of Energy Technologies and Policy, Vol. 3, No. 11, ISSN 2224-3232 (Paper) ISSN 2225-0573 (Online).

[11] Saurabh Kulkarni and Surya Santoso (2012), "Interrupting Short-Circuit Direct Current Using an AC Circuit Breaker in Series with a Reactor", Journal of Energy Technologies and Policy, Vol. 2012, ISSN 2090-181X.

[12] Md Shafiul Alam, Mohammad Ali Yousef Abido, Ibrahim ElAmin (2018), "Fault Current Limiters in Power Systems: A Comprehensive Review", Energies, Vol. 11, ISSN 1996-1073.

[13] Milap Akbari, Hemal Chavda, Jay Chitroda, Neha Kothadiya (2017), "Review paper on Fault analysis and its Limiting Techniques", International Research Journal of Engineering and Technology (IRJET), Volume: 04 Issue: 02, e-ISSN: 2395 -0056, p-ISSN: 2395-0072.

[14] Akpeh V. A, Madueme T. C, Ezechukwu (2015), “A New Approach to Implementing Fault Current Limiting Reactors (CLRS) On Feeders with Negligible Constant Power Losses", International Journal of Modern Engineering Research (IJMER), Vol. 5, Iss. 11, ISSN: 2249-6645.

[15] Mohsin Mumtaz, Hussain Sarwar Khan (2018), "Load Flow Analysis of CIGRE Benchmark Model Using ETAP", Proceedings of the International Conference on Renewable, Applied and New Energy Technologies, ICRANET-2018, pp. 19-22, Air University, Islamabad, Pakistan.

[16] Rohit Kapahi (2013), "Load Flow Analysis of $132 \mathrm{kV}$ Substation Using ETAP Software", International Journal of Scientific \& Engineering Research, Volume 4, Issue 2, ISSN: 2229-5518. 